\title{
Analisis Emisi Gas Buang Pada Mesin Diesel Menggunakan Bahan Bakar Campuran Solar dan Minyak Kelapa
}

\author{
Jemmy Charles Kewas ${ }^{1}$ \\ Program Studi Teknik Mesin Fakultas Teknik Universitas Negeri Manado \\ e-mail: jemmycharles@unima.ac.id
}

Augustinus R. Butarbutar ${ }^{2}$

Program Studi Ilmu Kesehatan Masyarakat Fakultas Ilmu Keolahragaan Universitas Negeri Manado e-mail: robinoben08@gmail.com

\begin{abstract}
ABSTRAK
Minyak kelapa merupakan salah satu sumber biosolar yang sangat potensial untuk dikembangkan dan berpotensi menggantikan bahan bakar solar dari fosil. Penelitian ini bertujuan untuk mengetahui emisi gas buang pada mesin Isuzu Panther $1200 \mathrm{cc}$ dengan menggunakan perbandingan campuran bahan bakar solar (S) dan minyak kelapa (MK) yakni solar murni atau 100\% S : 0\% MK, 95\% S : $5 \%$ MK, $90 \%$ S : $10 \% \mathrm{MK}, 85 \% \mathrm{~S}: 15 \% \mathrm{MK}$. Alat yang digunakan pada penelitian ini adalah Smokemeter dengan fungsi mengukur kepekatan asap hasil pembakaran. Metode penelitian adalah kuantitatif dengan pengujian eksperimental skala laboratorium. Hasil penelitian menunjukkan bahwa pembakaran campuran minyak solar murni kepekatan asapnya sebesar 80\%, pada campuran bahan bakar 95\% S : 5\% MK kepekatan asapnya sebesar 95\%. Pada campuran bahan bakar $90 \%$ S : 10\% MK dan campuran bahan bakar $85 \%$ S : 15\% MK memiliki nilai kepekatan asap yang sama yakni $100 \%$.
\end{abstract}

Kata kunci: Minyak kelapa, solar, emisi gas buang, kepekatan asap

ABSTRACT

Coconut oil is one of the potential biodiesel sources to be developed and has the potential to replace diesel fuel from fossils. This study aims to determine the exhaust emissions on the Isuzu Panther 1200 cc engine using a comparison of the mixture of diesel fuel (DF) and coconut oil (CO) which is pure diesel or 100\% DF:0\% CO, 95\% DF:5\% CO, 90\% DF:10\% CO, $85 \%$ DF:15\% CO. The research tools to use on this study is Smokemeter with a function of measuring the concentration of smoke from combustion. This research using quantitative method with laboratory scale experimental testing. The results showed that the combustion of diesel oil produce smoke concentration 80\%, in a fuel mixture of 95\% DF:5\% CO, the concentration of smoke is 95\%. In the fuel mixture of $90 \%$ DF: $10 \%$ CO and $85 \%$ DF :15\% CO has the same smoke density which is produce smoke concentration about 100\%.

Keywords: Coconut oil, Solar fuel, exhaust gas emissions, smoke density.

\section{PENDAHULUAN}

Pengembangan energi baru dan terbarukan menjadi salah satu topik riset unggulan nasional, mengingat bahan bakar sudah menjadi kebutuhan mendasar bagi keberlangsungan aktivitas manusia yang digunakan dalam berbagai macam bidang teknologi, baik pembangkit listrik, tranportasi udara laut darat, teknologi militer penggerak peluru kendali, roket, proyektil, bahkan dalam industri pembakaran menjadi jantung proses manufaktur. Pembakaran merupakan kunci penting kehidupan modern terutama menyangkut teknologi tinggi, hampir $90 \%$ energi didunia diperoleh dari pembakaran bahan bakar fosil (Wardana, 2008).

Minyak kelapa adalah merupakan salah satu sumber biodiesel yang sangat potensial dikembangkan dan dapat berpotensi menggantikan bahan bakar solar dari fosil. Salah satu bahan bakar alternatif yang ketersediannya cukup melimpah di Indonesia yaitu minyak dari kelapa atau minyak kelapa. 
Ketersediaan kelapa sebanding dengan ketersediaan kelapa maupun kopra. Indonesia sebagai negara tropis cukup melimpah dengan kelapa yang tersebar di beberapa daerah. Berdasarkan data Oil World tahun 2006, produksi kelapa Indonesia pada tahun 2005 mencapai 880 ribu ton, oleh karenanya minyak kelapa sangat berpotensi untuk dijadikan bahan bakar terbarukan pengganti bahan bakar fosil dalam hal ini solar (Tim Sekretariat MAPI, 2006).

Penelitian yang dilakukan pada pembakaran droplet campuran solar murni dan minyak kelapa (tanpa dilakukan transesterifikasi), didapati bawah campuran dengan prosentase campuran $80 \%$ solar dicampur 20\% minyak kelapa memiliki sudut injeksi yang mirip dengan solar murni (Kewas, 2013).

Kewas (2015) dalam penelitiannya tentang pengaruh campuran minyak kelapa dan bahan bakar solar terhadap karakteristik intermitensi api pembakaran, didapatkan hasil bahwa sudut penyebaran mengalami penyempitan seiring kenaikan komposisi minyak kelapa pada bahan bakar solar, yakni dari 13,60 untuk solar murni sampai 7,40 pada komposisi $100 \%$ minyak kelapa. Sedangkan dinamika pembakaran pada campuran minyak kelapa 10\%-30\% memiliki prilaku api yang tidak jauh beda dengan solar murni.

Bahan bakar minyak kelapa tersusun dari molekul-molekul triglyceride yang terdiri dari glycerol yakni alkohol dengan tiga rantai karbon sebagai tulang punggung (rantai utama) dan tiga cabang asam lemak dengan rantai 18 karbon atau 16 karbon, seperti terlihat pada gambar dibawah ini. Asam lemak merupakan rantai hidrokarbon lurus dan panjang yang berisi 12 sampai 24 atom karbon. Salah satu ujung molekul asam lemak berisi kelompok asam carboxylic $(\mathrm{COOH})$. Dari kelompok asam carboxylic ini bisa dihitung jumlah atom karbon. Ujung molekul yang lainnya adalah metil atau omega. Posisi ikatan ganda pertama menentukan apakah asam lemak tersebut omega 3 atau omega 6 (Wardana, 2008)

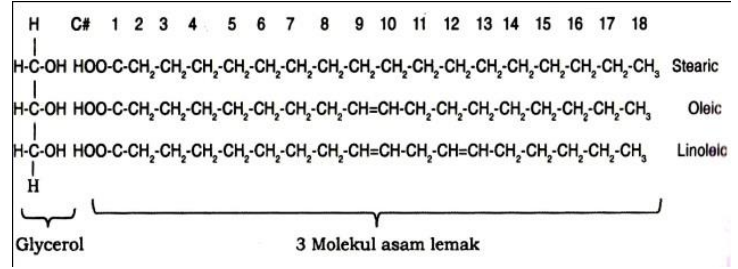

Gambar 1. Susunan ikatan molekul triglyceride (Wardana, 2008)

Penelitian tentang emisi gas buang pada variasi campuran biosolar minyak jarak dan solar yang dilakukan Hevandry, A. (2008), didapati hasil bahwa nilai emisi $\mathrm{CO} 2, \mathrm{SO} 2$ dan $\mathrm{CO}$ yang dihasilkan pada penggunaan campuran solar-biodiesel mengalami penurunan dibandingkan dengan solar murni, baik pada putaran $1600 \mathrm{rpm}$ maupun pada putaran $1800 \mathrm{rpm}$. Emisi yang dihasilkan dari penggunaan biodiesel sebagai campuran bahan bakar masih aman dan layak jika dibandingkan dengan standar emisi yang berlaku.

Minyak nabati mempunyai efisiensi dan daya mesin yang lebih besar dibanding dengan minyak diesel, karena suhu gas buang yang dihasilkan lebih rendah namun terjadi penurunan kualitas nilai kalor rata-rata $2 \%$. Dengan nilai kalor yang rata-rata lebih rendah $2 \%$, tetapi minyak nabati mempunyai angka cetana yang jauh lebih tinggi akan didapat keterlambatan penyalaan yang lebih pendek bila dibandingkan dengan minyak diesel. Adanya keterlambatan penyalaan yang lebih pendek (ignition delay) daya yang dihasilkan besar dan efektif, maka akan dihasilkan unjuk kerja yang optimum (Muryama, et. all, 2000)

Minyak vegetatif mempunyai nilai kalor lebih rendah dibanding minyak diesel tapi didapat angka cetana yang tinggi, namun emisi gas buang yang rendah untuk $\mathrm{CO}$ dan HC sedang NOx naik. Krishna C., R. dan Mc Donald, R. J. (2003) mengatakan bahwa 
emisi gas NOx paling rendah pada campuran B20 untuk berbagai macam perbandingan udara dan bahan bakar, karena pada B20 didapatkan suhu gas buang relatif rendah, ini dipercaya bahwa efisiensi meningkat terbukti karena suhu gas buang rendah karena angka cetana tinggi akan menghasilkan keterlambatan waktu penyalaan pembakaran lebih pendek.

Penelitian-penelitian tentang bahan bakar nabati yang telah dijadikan biodiesel telah banyak dilakukan, akan tetapi penelitian lebih dalam tentang minyak kelapa yang belum dilakukan transesterifikasi masih sedikit dikaji, oleh karena itu pengujian lebih lanjut akan bahan bakar nabati ini perlu dikaji lebih mendalam lewat instrumen emisi gas buang yaitu kepekatan asap hasil pembakaran. Maka penelitian ini menjadi perlu guna menganalisa lebih lanjut karakteristik performa motor bakar yang dikaji dari sisi emisi gas buang dalam hal ini kepekatan asap, melalui penggunaan beberapa variasi campuran bahan bakar solar dan minyak kelapa.

\section{METODE}

Penelitian ini menggunakan metode penelitian eksperimental dalam skala laboratorium. Penelitian ini dilaksanakan pada rentang waktu bulan Februari - November 2018 dilakukan di Laboratorium Bahan Bakar dan Teknologi Pembakaran VEDC Malang

Bahan yang digunakan pada penelitian ini adalah minyak kelapa dan solar. Sedangkan peralatan yang digunakan berupa mesin Isuzu Panther $1200 \mathrm{cc}$, dan smokemeter. Adapun mekanisme penelitian yang telah dilakukan adalah sebagai berikut:

1. Mencampur bahan bakar solar (S) dari minyak kelapa (MK) dari 100 S:0 MK, 95 S:5 MK, 90 S:10 MK, 85S :15 MK.

2. Mesin Izuzu Panterh 1200 cc disetting terlebih dahulu dimana dihububungkan ke alat smokemeter.

3. Atur gelas ukur untuk mengukur bahan bakar sebanyak 25 gr.
4. Mesin dihidupkan

5. Atur putaran mesin dari $1000 \mathrm{rpm}, 1500$ rpm, $2000 \mathrm{rpm}, 2500 \mathrm{rpm}$.

6. Ambil data kepekatan asap untuk masingmasing putaran mesin.

7. Dilakukan pengulangan pengambilan data untuk masing-masing campuran bahan bakar sebanyak lima kali.

8. Data diolah menggunakan statistic
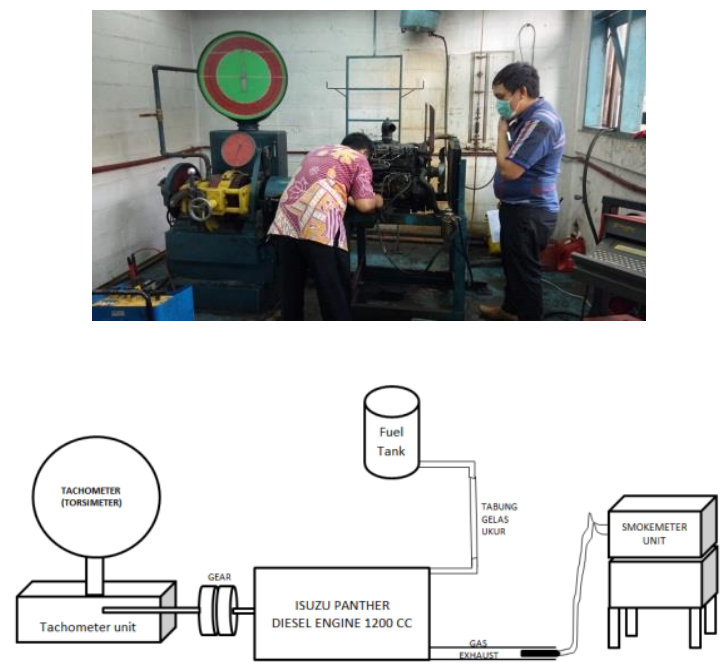

Gambar 2. Skema alat penelitian

\section{HASIL DAN PEMBAHASAN}

Hasil penelitian emisi gas buang yang diperoleh pada penelitian ini adalah kepekatan asap terendah terdapat pada pembakaran bahan bakar solar murni dan bahan bakar campuran 95:5 yakni masing-masing $80 \%$ dan 95\%, sedangkan pada pembakaran bahan bakar campuran 90:10 dan 85:15 memiliki kepekatan asap yang sama yakni 100\% (Tabel 1). 
Tabel 1. Hasil Perhitungan emisi gas buang pada mesin diesel menggunakan bahan bakar campuran solar dan minyak kelapa murni

\begin{tabular}{|c|c|c|c|}
\hline $\begin{array}{l}\text { Campuran } \\
\text { Bahan } \\
\text { (S) : (MK) } \\
\text { (Volume) }\end{array}$ & $\begin{array}{c}\text { Putara } \\
\text { n } \\
\text { Mesin } \\
\text { (RPM) }\end{array}$ & $\begin{array}{c}\text { Konsumsi } \\
\text { Bahan } \\
\text { Bakar } \\
\text { (gr/dtk) }\end{array}$ & $\begin{array}{c}\text { Emisi } \\
\text { Gas } \\
\text { Buan } \\
\mathbf{g} \\
(\%)\end{array}$ \\
\hline \multirow{4}{*}{ 100:0 } & 1000 & 3.01 & \multirow{4}{*}{80} \\
\hline & 1500 & 4.54 & \\
\hline & 2000 & 6.79 & \\
\hline & 2500 & 8.11 & \\
\hline \multirow{4}{*}{ 95:5 } & 1000 & 2.93 & \multirow{4}{*}{95} \\
\hline & 1500 & 5.34 & \\
\hline & 2000 & 6.91 & \\
\hline & 2500 & 7.81 & \\
\hline \multirow{4}{*}{$90: 10$} & 1000 & 2.83 & \multirow{4}{*}{100} \\
\hline & 1500 & 5.10 & \\
\hline & 2000 & 6.94 & \\
\hline & 2500 & 8.31 & \\
\hline \multirow{4}{*}{$85: 15$} & 1000 & 2.99 & \multirow{4}{*}{100} \\
\hline & 1500 & 4.89 & \\
\hline & 2000 & 6.65 & \\
\hline & 2500 & 7.58 & \\
\hline
\end{tabular}

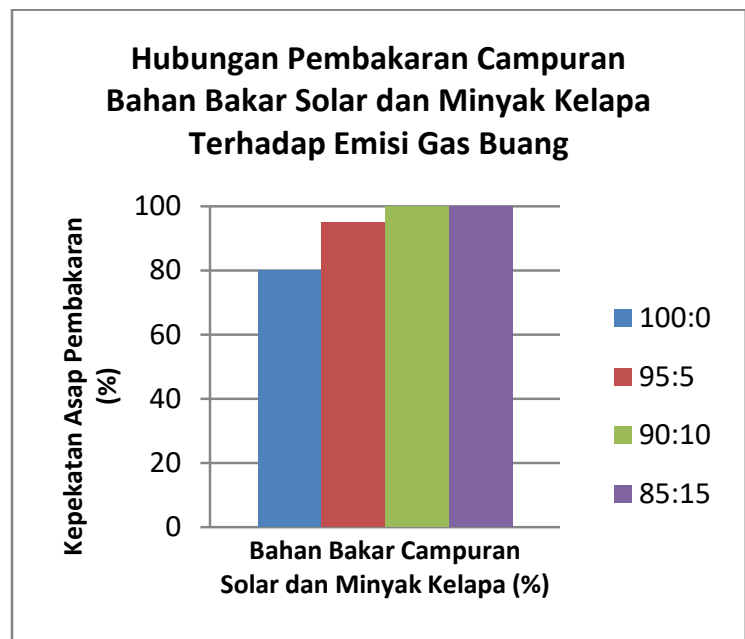

Gambar 3. Grafik hubungan campuran bahan bakar solar dan minyak kelapa muni terhadap emisi gas buang
Semakin besar penambahan fraksi minyak kelapa dalam bahan bakar solar yang digunakan dalam pembakaran mesin Isuzu Panther $1200 \mathrm{cc}$ menyebabkan meningkatnya kandungan karbon dalam fraksi bahan bakar tersebut, sehingga menyebabkan kebutuhan udara sebagai pengoksidasi menjadi semakin banyak, suplai oksigen yang tidak mencukupi uktuk mengoksidasi bahan bakar tersebut menyebabkan reaksi pembakaran yang tidak sempurna, hal ini dapat terlihat pada jelaga yang dihasilkan semakin tinggi pada setiap putaran mesin untuk masing-masing campuran bahan bakar.

Disamping itu sulit putusnya gliserol dalam rantai karbon minyak kelapa mengakibatkan pembakaran tidak terjadi secara sempurna, mengakibatkan produksi panas pembakaran tidak terlalu bagus dan berdampak pada pembentukan etil dalam rantai karbon tidak terjadi secara maksimal. Panas yang merupakan energi yang dibutuhkan untuk memutus ikatan karbon yang memiliki energi disiosasi tertentu khususnya pada rantai gliserol tidak mencukupi, sehingga rantai gliserol tidak putus dan tidak mampu membentuk serangkaian rantai etil dan metil. Rantai-rantai karbon inilah yang membentuk reaksi berantai pembakaran yang mampu menghasilkan reaksi pembakaran yang baik, ketidak mampuan membentuk rantai etil dan metil dalam reaksi pembakaran menyebabkan terjadi pembakaran yang buruk sehingga memproduksi asap atau jelaga yang banyak.

Hal lain yang mempengaruhi terjadinya peningkatan kepekatan asap pada pembakaran campuran bahan bakar solar dan minyak kelapa adalah viskositas, semakin tinggi kandungan minyak kelapa dalam solar maka nilai viskositas campuran bahan bakar ini mengalami peningkatan, sehingga menyebabkan pengkabutan bahan bakar di ruang bakar tidak menghasilkan atomisasi yang maksimal, sehingga menyulitkan terjadinya pembakaran. Atomisasi atau 
pengkabutan semprotan bahan bakar berperan penting dalam terjadinya proses rambatan ledakan, semakin terjadi pengkabutan maka reaksi oksidasi antara bahan bakan bakar dan oksigen terjadi secara maksimal, sehingga pembakaran yang baik memungkinkan terjadi. Viskositas yang tinggi adalah salah satu pemicu tidak maksimalnya pengkabutan fuel injektor ke ruang bakar.

\section{PENUTUP}

Kesimpulan

Semakin tinggi kandungan minyak kelapa pada bahan bakar solar menyebabkan semakin tinggi prosentase jelaga yang dihasilkan dalam proses pembakaran sehingga kepekatan asap terjadi peningkatan.

Saran

Perlunya dilakukan penelitian lebih lanjut tentang pengaruh temperatur pemanasan awal pada bahan bakar campuran solar dan minyak kelapa terhadap torsi mesin dan emisi gas buang

\section{UCAPAN TERIMA KASIH}

Kami menyampaikan terima kasih kepada Dirjen Penguatan Riset dan Pengembangan Kementerian Riset, Teknologi, dan Pendidikan Tinggi Republik Indonesia melalui skema Penelitian Dosen Pemula (PDP) tahun 2018 yang telah mendanai penelitian ini.

\section{DAFTAR PUSTAKA}

Havendri A. (2007). Kaji Eksperimental Emisi Gas Buangi Motor Bakar Diesel Menggunakan Bahan Bakar Campuran Biodiesel CPO Sawit dan Solar, Jurnal Teknika No. 28 Vol. 1 Thn. XIV, hal 7 - 12 , November 2007

Kewas, Jemmy, (2013). Pengaruh Variasi Persentase Minyak Kelapa pada

Jurnal Frontiers Vol 1 No 3, Desember 2018 249
Bahan Bakar Solar terhadap Sudut dan Intermitensi Atomisasi. Indonesian Green Technology Journal (IGTJ), E-ISSN.2338-1787. Vol. 2, No. 2, pp. 94-97

Kewas, Jemmy, (2015). Pengaruh Variasi Persentase Minyak Kelapa Pada Bahan Bakar Solar Terhadap Intermittensi Api Pembakaran. Indonesian Green Technology Journal (IGTJ), E-ISSN.2338-1787. Vol. 4, No. 3, pp. 56-60,

Krishna, C.R., and Mc Donald, R. J., (2003), Combustion Testing of a Biodiesel Fuel Blend. Brookhaven National Laboratory, New York.

Murayama, T., Fujiwara, Y., Noto, T., (2000) "Evaluating Waste Vegetable Oil As a Diesel Fuel", Proceedings of the Institution of Mechanical Engineers, Part D: Journal of Automobile Engineering. Sage Journals.

Tim Sekretariat MAPI, (2006). "Minyak Kelapa Sebagai BahanBakar Alternatif (Biofuel dan Biodiesel dari Kelapa)". http://www.dekindo.com/content/artik el/bahan_bakar.pdf, diakses tanggal 12 Oktober 2018

Wardana, I.N.G., (2008). "Bahan Bakar dan Teknologi Pembakaran”. Cetakan Pertama. PT. Danar Wijaya Brawijaya University Press, Malang. 


\section{RIWAYAT HIDUP PENULIS}

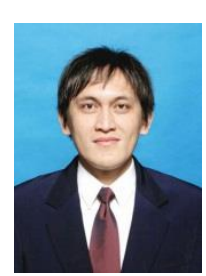

\section{Jemmy Charles Kewas,}

S.T., M.T.

Lahir di Desa Pakuure

Kabupaten Minahasa Selatan

Sulawesi Utara pada 08

Januari 1980. Staf pengajar di Program Studi Teknik Mesin Fakultas Teknik Universitas Negeri Manado. Studi S1 Teknik Mesin Universitas Kristen Cipta Wacana, Malang, lulus tahun 2005; S2 Teknik Mesin Kekhususan Konversi Energi Universitas Brawijaya, Malang, lulus tahun 2011. 